\title{
Expressed Sequence Tags from Roots and Nodule Primordia of Lotus japonicus Infected with Mesorhizobium loti
}

\author{
Carsten Poulsen and Lone Pødenphant \\ Department of Molecular and Structural Biology, Laboratory of Gene Expression, University of Aarhus, Gustav Wieds \\ Vej 10, DK Aarhus C, Denmark
}

Submitted 20 August 2001. Accepted 3 January 2002.

\begin{abstract}
Messenger RNA from young Lotus japonicus roots carrying root nodule primordia appearing after inoculation with Mesorhizobium loti bacteria were used to construct a cDNA expression library. Single-pass sequencing employing colony-polymerase chain reaction (PCR) and analysis of PCR products established a total of 2,397 new expressed sequence tags (ESTs). We have putatively identified 1,236 known and 484 hypothetical proteins coded by the corresponding mRNAs. The remaining cDNAs are unknown (316) or redundant overlapping cDNAs (361). We hope that this batch of ESTs will assist in the recognition of plant genes involved during development of nitrogen-fixing root nodules.
\end{abstract}

Additional keywords: legumes, root nodule development.

Legume research employs several model species, one of which is Lotus japonicus (Handberg and Stougaard 1992; Szczyglowski et al. 1997). L. japonicus is diploid, has a small genome and a short generation time, and represents the determinate root nodule type. In addition, L. japonicus has advantageous properties in tissue culture and is a capable recipient of Agrobacterium tumefaciens-mediated DNA transfer and transposon tagging (Quaedvlieg et al. 1998; Schauser et al. 1998; Wegel et al. 1998). These procedures have yielded mutations that led to the identification of a key regulatory gene in root nodule inception, Nin (Schauser et al. 1999). Efforts in genome mapping using molecular markers and sequence polymorphism in different populations (N. N. Sandal, J. Stougaard, personal communication), and chemical mutagenesis programs for analyses of root nodule development or arbuscular mycorrhiza (Imaizumi-Anraku et al. 2000; Senoo et al., 2000) are underway. With these approaches, map-based cloning may identify new genes. Differential display cDNAs (Szczyglowski et al. 1997) and analysis of expressed sequence tag (EST)cDNA sequences from libraries of different organs and development stages, employing micro array or DNA-chip technology, will suggest other genes of importance. In order to contribute to such a project, we have begun sequencing cDNAs from L. japonicus Mesorhizobium loti-infected roots and root nodule primordia (Ljirnpest cDNA library).

Corresponding author: Carsten Poulsen, Telephone: +45 89425007; Fax:+45 86123178; E-mail: CHP@ mbio.aau.dk

\section{RESULTS AND DISCUSSION}

We report the single-pass sequencing of 3,684 cDNAs from L. japonicus, of which 2,397 sequences were inserted into six National Center for Biotechnology Information (NCBI) GenBank batch submission forms. These sequences went through a NCBI GenBank BlastN or BlastX procedure for identification of the gene or the protein. Whenever possible, the sequences were annotated before submission. GenBank accession numbers for six batches of ESTs from the Ljirnpest cDNA library are: AI967297 to AI967914 plus AI967920 to AI967923, AW163869 to AW164183, AW428653 to AW428932, BE122430 to BE122644, BF177456 to BF177921, and BG661984 to BG662483. The first three batches $(1,221$ ESTs) were used for blast searches in the nonredundant (NR) nucleotide sequence database (BlastN: nucleotide sequence homology at the level of genes and mRNAs, and BlastX: homology at the level of nucleotide sequences translated into protein primary structure). After the release of large numbers of ESTs from soybean, Medicago truncatula, and $L$. japonicus in early 2000, systematic BlastN searches in the $\mathrm{NCBI} /$ dbest database were performed on all sequences in the last three batches to pinpoint cDNAs/mRNAs specific for our library and confirm legume sequences not present in nonlegume databases. We observe that, of the identified sequences among these 1,176 ESTs, 95\% hit other plant EST primary targets, $81 \%$ hit legume EST primary targets, and approximately $25 \%$ of the tags correspond to other L. japonicus ESTs (Asamizu et al. 2000; Endo et al., 2000; (M. K. Udvardi, unpublished data).

Summaries of search results available online focus on putative protein identifications in alphabetical order. The primary blast hits of BlastN NR, BlastX NR, and BlastN dbest searches that seem to give specific identification are entered in columns. When this was not possible, the "unknown" tag was given. Also, we show the approximate cDNA size and putative cDNA variant number, possibly reflecting gene polymorphism. Direct links to NCBI from this site will aid further identification in the future.

Next, we classified the putatively identified proteins according to their presumed function in a variety of cellular processes (Table 1). From the 2,397 ESTs submitted, we have identified 1,236 different nonredundant cDNAs, which identify a similar number of apparently different proteins. These hit all imaginable classes of protein function, ranging from DNA and RNA metabolism to transcription factors, mRNA translation, and cellular protein compartmentalization. Also, various enzymes appearing in metabolic processes and signal transduc- 
tion processes were identified, as well as proteins that may play roles in stress or infection. We note a high number of different $\mathrm{Cab}$ (light-harvesting chlorophyll $\mathrm{a} / \mathrm{b}$ binding protein) ESTs, together with other photomorphogenesis-related mRNAs, in the library from nonphotosynthetic tissues. Interestingly, we find only two different ESTs, derived from ribulose 1,5-bisphosphate carboxylase-oxygenase (RUBISCO) $r b c S$ mRNAs ubiquitous in aerial parts of light-grown plants. Also, several ESTs for thioredoxin, glutaredoxin, and cytochrome P450 monoxygenases were isolated, reflecting a high demand for electron flow and oxidoreductive processes. We observe a number of diverse Myb-like proteins, ubiquitous factors in the cellular transcription machinery. Finally, a group of ESTs represent "other" proteins, to which we cannot assign clear roles in a plant context (e.g., calcineurin, presenilin, separation anxiety protein, synaptobrevin-like, and others). In general, this distribution pattern is also reflected in other L. japonicus EST data collections (Asamizu et al. 2000; Endo et al. 2000).

We have isolated $10 \mathrm{cDNAs}$ established as specific for early root nodule development (e.g., those encoding the nod factorbinding lectin-nucleotide phosphohydrolase) (Roberts et al.

Table 1. Protein classes identified from expressed sequence tag collection ${ }^{\mathrm{a}}$

\begin{tabular}{|c|c|}
\hline Classes & Number found \\
\hline $80 \mathrm{~S}$ ribosomal proteins & 90 \\
\hline $70 \mathrm{~S}$ ribosomal proteins & 4 \\
\hline Translation factors & 38 \\
\hline Chaperones, assembly & 34 \\
\hline Protein sorting, secretion, endocytosis & 23 \\
\hline Membrane assembly and function & 19 \\
\hline Plasma membrane and cell wall & 26 \\
\hline Transporters and channels & 58 \\
\hline Nuclear matrix & 28 \\
\hline Filament and cytoskeleton structure and function & 31 \\
\hline RNA-binding & 24 \\
\hline DNA-binding & 15 \\
\hline RNA- and DNA-metabolism & 19 \\
\hline Hormonal regulation, infection and stress & 117 \\
\hline Growth regulators and signal transduction & 16 \\
\hline Transcription complex proteins and factors & 53 \\
\hline Cell cycle and cell division & 9 \\
\hline GTP binding and GTPases & 25 \\
\hline GTPase regulators & 8 \\
\hline Protein kinases and receptors & 58 \\
\hline Kinase regulators & 16 \\
\hline Unspecified regulators & 11 \\
\hline Protein phosphatase related & 10 \\
\hline N-metabolism & 4 \\
\hline Amino acid -metabolism & 39 \\
\hline S-metabolism & 3 \\
\hline Nucleotide-metabolism & 8 \\
\hline Lipo-compound metabolism & 33 \\
\hline Carbon- and carbohydrate-metabolism & 51 \\
\hline Energy-conversion and coupling, ATPases & 28 \\
\hline Electron transport, Redox proteins & 42 \\
\hline Vitamin metabolism & 13 \\
\hline Synthesis of secondary metabolites & 49 \\
\hline Embryogenesis and Seeds & 15 \\
\hline Photomorphogenesis and Photosynthesis & 22 \\
\hline Nodule Development and Function & 10 \\
\hline Flower Development & 3 \\
\hline Metal binding & 11 \\
\hline Apoptosis* & 3 \\
\hline Ubiquitin-complex and protein-metabolism & 71 \\
\hline Others & 100 \\
\hline Putatively identified proteins & 1,236 \\
\hline Hypothetical proteins & 484 \\
\hline Unknown & 316 \\
\hline Redundant ESTs, multiply covering mRNAs & 361 \\
\hline Total & 2,397 \\
\hline
\end{tabular}

${ }^{a}$ Table information is presented in greater detail online.
1999), eNOD40 (Flemetakis et al. 2000; Yang et al. 1993), eNOD8, eNOD18 (Hohnjec et al., 2000), and the previously mentioned NIN regulatory protein. Interestingly, leghemoglobin cDNAs were absent, although homologs of a few other "late" nodulins were sequenced: NOD21, NOD26 [aquaporin, membrane intrinsic protein (MIP)], SAT1 (Kaiser et al. 1998), annexin (De Carvalho Niebel et al. 1998), and the unknown protein MTD1 (Curioni et al. 2000).

The fact that we dealt with very early root nodule differentiation events somewhat diluted by mRNA populations of overall root tissues may explain why we have isolated only a few ESTs corresponding to mRNAs that already have been implicated in root-nodule events. However, a large proportion of gene products probably will be found to be root-nodule enhanced or root-nodule specific when analyzed in greater detail. Examples of these could be calmodulins (Webb et al. 2000) and other signal transduction proteins such as G-proteins (Pingret et al. 1998), protein phosphatases (Kapranov et al.

Table 2. Examples of probable multigene families ${ }^{\mathrm{a}, \mathrm{b}}$

\begin{tabular}{|c|c|}
\hline Protein & Number of tags \\
\hline Actin & 5 \\
\hline Amino acid permease/carrier & 6 \\
\hline Ankyrin & 4 \\
\hline Annexin & 4 \\
\hline Aquaporin & 18 \\
\hline Ascorbic acid peroxidase & 5 \\
\hline Arf1 small GTP-binding & 7 \\
\hline Calmodulin & 6 \\
\hline Calreticulin & 4 \\
\hline Cytochrome P450/monooxyg. & 16 \\
\hline Dormancy associated protein & 4 \\
\hline DnaJ-type chaperone & 11 \\
\hline Elongation factor 1a & 6 \\
\hline Endo 1,4-beta-D-glucanase & 6 \\
\hline Epoxide Hydrolase & 4 \\
\hline Expansin & 4 \\
\hline $14-3-3$ protein & 10 \\
\hline Glutaredoxin & 4 \\
\hline Glutathione S-transferase & 8 \\
\hline Glycine rich RNA-binding & 4 \\
\hline Histone deacetylase & 4 \\
\hline Heat Schock Protein 70/71 & 7 \\
\hline Heat Schock Protein 80 & 3 \\
\hline Isoflavone Reductase & 4 \\
\hline Major Latex Protein & 6 \\
\hline Late Embryogenesis Related & 5 \\
\hline Light Harvesting Chl a/b (Cab)-PS2 & 11 \\
\hline Lipoxygenase & 9 \\
\hline Lysophospholipase & 3 \\
\hline Methionine synthase & 6 \\
\hline Metallothionein & 3 \\
\hline Myb factor & 10 \\
\hline NAD dehydrogenase & 4 \\
\hline Peroxidase & 16 \\
\hline Protein phosphatase $2 \mathrm{c}$ & 4 \\
\hline Profilin & 2 \\
\hline Proline rich (HRP, extensin) & 16 \\
\hline Serine amino transferase & 2 \\
\hline Serpins & 2 \\
\hline Subtilisin-like & 4 \\
\hline Sugar transporter & 5 \\
\hline Thiol Protease & 10 \\
\hline Thioredoxin & 4 \\
\hline Alpha-tubulin & 3 \\
\hline Beta-tubulin & 3 \\
\hline Ubiquitin & 10 \\
\hline Ubiquitin conjugating enzyme & 12 \\
\hline
\end{tabular}

a Number of nonoverlapping expressed sequence tags (ESTs) coding for the specified protein are shown. Some of the protein species of these families are represented by overlapping ESTs.

b Table information is presented in greater detail online. 
1999), and phospholipase $\mathrm{C}$ and phosphatidyl inositol-4phosphate-5-kinase (PIP) (den Hartog et al. 2001). We also sequenced cDNAs for a large number of protein kinase-like proteins. Protein kinases participate in the regulation of metabolism and in both signal perception and the funneling of signals into developmental pathways; therefore, they should be closely investigated. ESTs for the SAR1, Arf1 SMG-proteins and an LjRab5A GTPase (Borg et al. 1997), together with many other ESTs possibly involved in vesicle trafficking, may also be of importance during rhizobial invasion and symbiosome formation. Many of the ESTs in the classes of hormone regulation, infection, stress, and environmental response may show up during root nodule development.

A total of 484 unique ESTs are homologous to hypothetical proteins, encoded primarily in the A. thaliana genome sequence (Arabidopsis Genome Initiative 2000). For another 316 unique ESTs, we did not identify homologs in the NR or dbest databases. It appears that this group of cDNAs contain very short poly $(\mathrm{A}+)$-proximal sequences or longer sequences that cover $5^{\prime}$ noncoding information. Much larger sets of ESTs, or extensive genome sequence information from L. japonicus, are necessary for identification or verification of these ESTs. The classes of hypothetical and, in particular, the unknown mRNAs should be investigated with respect to root nodule development.

The last group of cDNAs consists of 361 redundant ESTs, that overlap and have partially identical sequences when compared to the remaining 2,036 ESTs. It is clear that the sequences in this group are derived from independent cDNA synthesis and cloning events. We have not established, per se, how many different mRNAs this group encompasses. It appears that the ESTs here stem from mRNAs that are abundant in the cells of the tissue used for RNA isolation (e.g., mRNAs for the aquaporin-like proteins, extensins [proline/hydroxyproline-rich proteins], the RD22-like dehydration responsive protein, major latex-like [ripening-related] proteins, late embryogenesis abundant [LEA-like] proteins, ubiquitin, the ubiquitin conjugating enzyme, and finally, some ribosomal protein mRNAs are represented by multiple ESTs).

Interestingly, the redundant cDNAs overlap the list of mRNAs and gene products expressed from putative multigene families. Table 2 presents the number of EST classes for some putatively polymorphic proteins, which may reflect gene multiplication. Complete sequencing of all these cDNAs and a full sequence alignment study will resolve this. We have not compared the putative multigene family members at the level of protein primary structures, although the overlapping of protein sequences derived from nonaligning mRNAs would sustain the suggested gene diversity. To aid such procedures, it is also likely that the Kazusa DNA Research Institute L. japonicus database, encompassing approximately 30,000 ESTs, can be used for assembly of tentative consensus (TC) sequences (Quackenbush et al. 2001), clusters of ESTs derived from specific gene transcripts.

We observe that mRNAs for aquaporins, extensins, peroxidases, lipoxygenases, thiol proteases, ubiquitins, and ubiquitin-conjugating enzymes contribute the largest number of variant cDNAs. This probably reflects the fact that cells in the organs and tissues used for library construction demand both transcript variation and the presence of particular mRNAs in high amounts, a consequence of local requirements for a given protein species. This can be further studied by creating TCs, described above, to be used for blast analyses of tissue- and organ-specific EST libraries, resulting in electronic Northern blots (Quackenbush et al. 2001). These may give hints about gene expression patterns based on relative EST abundance. However, we believe that the number of L. japonicus ESTs and libraries is not yet sufficient for such an exercise and, further, may rapidly be overtaken by results of microarray and DNA-chip analyses.

In this research, we have only scratched the surface of gene complexity in L. japonicus. However, in a study combining and comparing L. japonicus data with data from other legumes, from Arabidopsis thaliana, and from other nonleguminous plant resources found on NCBI or The Institute for Genomic Research websites, the genetic ore that contributes to formation of the important legume symbiotic organ will be more fully revealed.

\section{MATERIALS AND METHODS}

Messenger RNA was prepared from seedling roots infected with Mesorhizobium loti culture during seed germination. The roots were harvested between 5 and 12 days after inoculation (Borg et al. 1999; Jorgensen et al. 1999). Synthesis of cDNA was primed with XhoI site-tagged oligodT, and cDNAs were $5^{\prime}$ tagged with 5'-GAATTCGGCACGAG-3' (EcoRI). Tagged cDNAs were inserted in the Stratagene $\lambda$ HybriZAP vector. The library was manipulated in Escherichia coli XL1-Blue $\mathrm{MRF}^{\prime}$ and in E. coli XLOLR cells, as described in the HybriZAP manual (Stratagene, La Jolla, CA, U.S.A.). Ampicillin-resistant colonies from 0.7-ng library plasmid DNA, pAD-GAL4 recombinant plasmids obtained after HybriZap mass-excision and transformed into $E$. coli XL1-Blue MRF', were transferred onto 45 Luria-Bertani-Amp plates in a microtiter plate (MTP) replica format. Colony-polymerase chain reaction (PCR) employed the 21-mer T7 sequencing primer 5'-GTAATACGACTCACTATAGGG-3' and the 26-mer GAL4AD primer 5'-CCACTACAATGGATGATGTATATAAC-3'. Thermocycling was initiated at $94^{\circ} \mathrm{C}$ for $4 \mathrm{~min}$, followed by 35 cycles at 94,50 , and $72^{\circ} \mathrm{C}$ for 1,1 , and $2 \mathrm{~min}$, respectively, and terminated at $72^{\circ} \mathrm{C}$ for $7 \mathrm{~min}$. PCR fragments were purified by passage through Sephacryl S-400. Amplicons obtained using the GAL4AD primer and the Thermosequenase sequencing reagents (Amersham Biosciences UK, Little Chalfont, Buckinghamshire, U.K.) were sequenced using ABI310 and ABI377 Genetic Analyzers (PerkinElmer Inc., Boston). MTP-format liquid cultures were transferred to 45 sealed 96-well microtiter plates, and pools of $10-\mu$ l aliquots of single colony cultures mixed in cryotubes were stored at $-80^{\circ} \mathrm{C}$. Corresponding digital sequence files were edited on Power Macintosh computers employing Sequencher 2.0.1 and MacDNAsis 3.5 software to eliminate reading errors, bad sequences, untrustworthy sequence segments, and duplicated cDNAs.

\section{ACKNOWLEDGMENTS}

We thank our colleagues for their help and understanding. This research was funded by the Danish Biotechnology Program and by a grant from the Novo-Nordisk Foundation.

\section{LITERATURE CITED}

AGI, The Arabidopsis Genome Initiative. 2000. Analysis of the genome sequence of the flowering plant Arabidopsis thaliana. Nature 408:796815.

Asamizu, E., Nakamura, Y., Sato, S., and Tabata, S. 2000. Generation of 7137 non-redundant expressed sequence tags from a legume, Lotus japonicus. DNA Res. 7:127-130.

Borg, S., Brandstrup, B., Jensen, T. J., and Poulsen, C. 1997. Identification of new protein species among 33 different small GTP-binding proteins encoded by cDNAs from Lotus japonicus, and expression of corresponding mRNAs in developing root nodules. Plant J. 11:237-250.

Borg, S., Podenphant, L., Jensen, T. J., and Poulsen, C. 1999. Plant cell growth and differentiation may involve GAP regulation of Rac activity. FEBS (Fed. Eur. Biochem. Soc.) Lett. 453:341-345.

Curioni, P. M. G., Reidy, B., Flura, T., Vogeli-Lange, R., Nosberger, J., and 
Hartwig, U. A. 2000. Increased abundance of MTD1 and MTD2 mRNAs in nodules of decapitated Medicago truncatula. Plant Mol. Biol. 44:477-485.

de Carvalho Niebel, F., Lescure, N., Cullimore, J. V., and Gamas, P. 1998 The Medicago truncatula MtAnn1 gene encoding an annexin is induced by Nod factors and during the symbiotic interaction with Rhizobium meliloti. Mol. Plant-Microbe Interact. 11:504-513.

den Hartog, M., Musgrave, A., and Munnik, T. 2001. Nod factor-induced phosphatidic acid and diacylglycerol pyrophosphate formation: A role for phospholipase C and D in root hair deformation. Plant J. 25:55-65.

Endo, M., Kokubun, T., Takahata, Y., Higashitani, A., Tabata, S., and Watanabe, M. 2000. Analysis of expressed sequence tags of flower buds in Lotus japonicus. DNA Res. 7:213-216.

Flemetakis E., Kavroulakis N., Quaedvlieg N. E., Spaink H. P., Dimou M., Roussis A., and Katinakis P. 2000. Lotus japonicus contains two distinct ENOD40 genes that are expressed in symbiotic, nonsymbiotic, and embryonic tissues. Mol Plant-Microbe Interact. 13:987-994.

Handberg, K., and Stougaard, J. 1992. Lotus japonicus, an autogamous, diploid legume species for classical and molecular genetics. Plant J. 2:487-496.

Hohnjec, N., Kuster, H., Albus, U., Frosch, S. C., Becker, J. D., Puhler, A., Perlick, A. M., and Fruhling, M. 2000. The broad bean nodulin VfENOD18 is a member of a novel family of plant proteins with homologies to the bacterial MJ0577 superfamily. Mol. Gen. Genet. 264:241-250.

Imaizumi-Anraku, H., Kouchi, H., Syono, K., Akao, S., and Kawaguchi, M. 2000. Analysis of ENOD40 expression in alb1, a symbiotic mutant of Lotus japonicus that forms empty nodules with incompletely developed nodule vascular bundles. Mol. Gen. Genet. 264: 402-410.

Jorgensen, J. E., Gronlund, M., Pallisgaard, N., Larsen. K., Marcker, K A., and Jensen, E. O. 1999. A new class of plant homeobox genes is expressed in specific regions of determinate symbiotic root nodules. Plant Mol. Biol. 40:65-77.

Kaiser, B. N., Finnegan, P. M., Tyerman, S. D., Whitehead, L. F. Bergersen, F. J., Day, D. A., and Udvardi M. K. 1998. Characterization of an ammonium transport protein from the peribacteroid membrane of soybean nodules. Science 281:1202-1206

Kapranov, P., Jensen, T. J., Poulsen, C., de Bruijn, F. J., and Szczyglowski K. 1999. A protein phosphatase 2C gene, LjNPP2C1, from Lotus japonicus, induced during root nodule development. Proc. Natl. Acad. Sci. U.S.A. 96:1738-1743.

Quaedvlieg, N. E. M., Schlaman, H. R. M., Admiraal, P. C., Wijting, S. E., Stougaard, J., and Spaink, H. 1998. Fusions between green fluorescent protein and beta-glucuronidase as sensitive and vital bifunctional reporters in plants. Plant Mol. Biol. 38:861-873.

Quackenbush, J. Cho, J., Lee, D., Lieng, F., Holt, I., Karamycheva, S. Parvizi, B., Pertea, G., Sultana, R., and White, J. 2001. The TIGR gene indices: Analysis of gene transcript sequences in highly sampled eukaryotic species. Nucleic Acids Res. 29:159-164.
Pingret, J. L., Journet, E. P., and Barker D. G. 1998. Rhizobium nod factor signaling. Evidence for a $\mathrm{G}$ protein-mediated transduction mechanism. Plant Cell 10:659-672.

Roberts, N. J., Brigham, J., Wu, B., Murphy, J. B., Volpin, H., Phillips, D. A., and Etzler, M. E. 1999. A Nod factor-binding lectin is a member of a distinct class of apyrases that may be unique to the legumes. Mol. Gen. Genet. 262:261-267.

Schauser, L., Handberg, K., Sandal, N., Stiller, J., Thykjaer, T., Pajuelo, E., Nielsen, A., and Stougaard, J. 1998. Symbiotic mutants deficient in nodule establishment identified after T-DNA transformation of Lotus japonicus. Mol. Gen. Genet. 259:414-423.

Schauser, L., Roussis, A., Stiller, J., and Stougaard, J. 1999. A plant regulator controlling development of symbiotic root nodules. Nature 402:191-195

Senoo K., Solaiman M. Z., Kawaguchi M., Imaizumi-Anraku H., Akao S., Tanaka A., and Obata H. 2000. Isolation of two different phenotypes of mycorrhizal mutants in the model legume plant Lotus japonicus after EMS-treatment. Plant Cell Physiol. 41:726732.

Szczyglowski, K., Hamburger, D., Kapranov, P., and de Bruijn, F. J. 1997. Construction of a Lotus japonicus late nodulin expressed sequence tag library and identification of novel nodule-specific genes. Plant Physiol 114:1335-1346

Webb, K. J., Skøt, L., Nicholson, M. N., Jørgensen, B., and Mizen, S. 2000. Mesorhizobium loti increases root-specific expression of a calcium-binding protein homologue identified by promoter tagging in $\mathrm{Lo}$ tus japonicus. Mol. Plant-Microbe Interact. 13:606-616.

Wegel, E., Schauser, L., Sandal, N., Stougaard, J., and Parniske, M. 1998. Mycorrhiza mutants of Lotus japonicus define genetically independen steps during symbiotic infection. Mol Plant-Microbe Interact. 11:933936.

Yang, W. C., Katinakis, P., Hendriks, P., Smolders, A., de Vries, F., Spee, J., van Kammen, A., Bisseling, T., and Franssen, H. 1993. Characterization of GmENOD40, a gene showing novel patterns of cell-specific expression during soybean nodule development. Plant J. 3:573-585.

\section{AUTHOR RECOMMENDED INTERNET RESOURCES}

The Institute for Genomic Research TIGR database: http://www.tigr. org/tdb/index.shtml

Kazusa DNA Research Institute Department of Plant Gene Research L. japonicus database: http://www.kazusa.or.jp/en/plant/lotus/EST/

National Center for Biotechnology Information GenBank: http://www. ncbi.nih.gov

Carsten Poulsen search result summaries and Table 2 data found at http: //www.mbio.aau.dk/ chp/ABZlist.html

Carsten Poulsen Table 1 presented in greater detail at http://www. mbio.aau.dk/ chp/Table1.html. 